\title{
Association of Knee Osteoarthritis with Difficulty During Activities of Daily Life in Elderly Females: A Cross Sectional Study
}

\section{Sidra Firdous lqbal' ${ }^{1}$, Arzoo Nawaz $^{2}$, Arooj Fatima ${ }^{3}$, Ashfaq Ahmad ${ }^{4}$}

${ }^{1-3}$ Senior Lecturer, ${ }^{4}$ Assistant Professor

1-4 University of Lahore

Author's Contribution

1-2Conception and design, Collection and assembly of data, Analysis and interpretation of the data, ${ }^{2-3} \mathrm{Critical}$ revision of the article for important intellectual content, Statistical expertise ${ }^{1}$ Final approval and guarantor of the article.

Article Info.

Received: Nov 15, 2019

Acceptance: Dec 30, 2020

Conflict of Interest: None

Funding Sources: None

Address of Correspondence

Dr Sidra Firdous lqbal

Email Id: sidfirdous.99@gmail.com

Cite this article as: Iqbal SF, Nawaz

A, Fatima A, Ahmad A. Association of

Knee Osteoarthritis with Difficulty

During Activities of Daily Life in

Elderly Females: A Cross Sectional

Study. JRCRS. 2021; 9(1). 10-13.

DOI:

https://dx.doi.org/10.53389/JRCRS.20 $\underline{21090102}$

\section{A B S T R A C T}

Objectives: This study aims to determine association between knee osteoarthritis (OA) and difficulty during activities of daily living in elderly female patients.

Methodology: The cross-sectional study was carried out on 167 patients that presented with osteoarthritis of the knee in various hospitals of Lahore city, sample size was calculated by using epi-tool. Females aged 45-82 years with diagnosed knee OA of either one or both knees evaluated by using radiographs, were included in study. Degree of difficulty while performing ADL's was assessed by using knee OA- related health assessment survey (WOMAC Osteoarthritis Index). Data was analyzed using SPSS 21.0. Results: The resulting mean age of the elderly female patients was $58.33+8.836$ ranging from 45 to 82 years. The results showed incidence of knee osteoarthritis in the elderly females as $91(54.5 \%)$ with OA in left knee, 63(37.7\%) with right knee OA and 13(7.8\%) with bilateral knee OA. A significant association among knee $\mathrm{OA}$ and difficulty during ascending stairs $(0.018)$, difficulty during rising from sitting $(0.002)$, difficulty during bending to floor (0.042), difficulty during getting in/out of car (0.03), difficulty in putting on socks (0.045), difficulty in taking off socks (0.001), difficulty getting in/out of bath (0.024), difficulty during on off toile (0.022) exits.

Conclusion: The propositions of these results focus the intense influence of Knee OA on daily living activities that have not been clearly recognized in the previous studies. These results proposed that a decline in chore-explicit knee pain according to severity of the disease can increase stages of physical activity.

Key words: Activities of Daily Living, Difficulty, Knee Osteoarthritis.

\section{Introduction}

Knee Osteoarthritis can be termed as a diverse set of disorders which results in joint associated clinical manifestations that are interconnected with damaged coherence of the articular cartilage of the joint along with comparable alterations over the boundaries of the joint composition and its principal primary bone. Despite the fact that there is insufficient innervation to the articular cartilage of the joint, the deficits in the cartilage are correlated to the symptoms because of which clinical signs such as pain may proceed from these

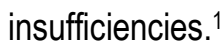

The pervasiveness of $O A$ is the highest in older people that intensifies through time and is more frequent among women than among men. ${ }^{1}$ Knee $\mathrm{OA}$ is a main source of pain and disability disturbing a substantial percentage of elder population. In patients diagnosed with osteoarthritis of the knee joint, the foremost clinical sign to be reported is mostly while ascending the stairs. ${ }^{3,4}$ The cause of pain in knee OA has not been discovered yet. The previous evidence of reasoning can be classified into organic sources like cartilage deteriorating and osteophyte development into nearby tissues of the joint. ${ }^{5}$ 
Approximately half of the adult population above the age of fifty report knee pain in a 1-year period. In older adults limitation of physical function has been linked with the commencement of knee pain. Future prognosticators indicate knee pain is solid predictor of dependency and disability as it is associated with impaired physical functioning. Patients have more severe symptoms and greater level of difficulty while weight bearing with generalized knee pain. In comparison those with medial knee joint pain have better physical functioning score but have more pain during standing position. However, both seem to have same disease severity and characteristics related to psychosocial aspects despite of alterations in symptoms and functional ability. ${ }^{6}$

Numerous studies have predicted the association of muscle weakness with knee joint OA but very few studies have evaluated this till date. Moreover, a change is said to be reported in the character of knee pain during weight bearing of the joint when compared to non-weight bearing pain of the same joint(7). The prevalence of osteoarthritis of the hip or the hand and knee upsurges around menopause and it is more prevalent in women than men. A significant part of hormonal influences has been deduced by numerous authors regarding advancement of $O A$. Other factors such as diminished cartilage bulk, destruction of the bone or absence of the power of muscle may be used to describe the alteration between women and men although the results are contradictory.

Obesity or overweight may be termed as Body Mass Index which refers to index of $>30 \mathrm{~kg} / \mathrm{m} 2$ that has a strong relation with osteoarthritis of the knee while the association between BMI of less than $25 \mathrm{~kg} / \mathrm{m} 2$ and $\mathrm{OA}$ of knee is minimal yet noteworthy. ${ }^{8}$

Alternative kind of physical movement is exercise therapy which is usually programmed and done by occupational therapists and physical therapists. ${ }^{10}$ The highest management in osteoarthritis of knee joint is chiefly symptomatic relief of the painful joint. ${ }^{11}$

Rehabilitation of knee OA normally involves anaerobic and aerobic workouts, managing of weights, strengthening of the weakened muscles, self-supportive exercises and attentiveness, biological and mechanical control and participation in activities of daily life..$^{12}$ As the impact of knee osteoarthritis lies particularly high in females, such theories increase the urge upon finding evidence on this matter. Struggle exists when mostly women rather than men are exposed to knee $O A$ and hence the burden of osteoarthritis to health sector budget is increased. ${ }^{9}$ This research was created on an hypothesis that an association might exist between knee OA and difficulty during activities of daily living among elderly female knee osteoarthritis patients. Yet, no studies upto date have assessed this association.

\section{Methodology}

A cross-sectional study was conducted after getting Institutional Review Board approval from University of Lahore from June to Oct 2019.The data was gathered from Sheikh Zayed hospital in Lahore, University of Lahore Teaching hospital Lahore, Services hospital in Lahore, and some of the data was collected from HaqOrthopedic Hospital in Lahore. Sample was collected through non-probability convenient sampling. The 167 women were enrolled for the study from various hospitals of Lahore mentioned above. Females of age 45-82 years with detected knee osteoarthritis of either one or both knees, evaluated by using $x$-rays in weight bearing of the patient and ability to stroll individualistically on a flat land unaided by any sort of assistive devices were included in the study. Patients with any previous history any diseases like bone tuberculosis, rheumatoid arthritis and herniated disc. Also patient with history of knee surgery and any fall history were not checked out as suitable for inclusion. WOMAC questionnaire was used to assess the participants for difficulty in accomplishing activities of daily living. WOMAC is self-rating scale used to assess the individuals for degree of difficulty in performing ADLs. All data analysis was accomplished using SPSS version 21. Chi-Square test was applied to check association between two variables; $p$-value less than 0.05 were considered statistically significant.

\section{Results}

The mean age of subjects was $58.33+8.836$ where the total number of subjects was 167 . Descriptive results for age of participants was shown in Table I. The association between two variables; knee osteoarthritis and activities of daily living were shown in Table II below $P$-value of $<0.05$ shows there is relationship between two 
variables and $>0.05$ shows no association. "a" represents the alpha level in the chi square results which means the degree of freedom that is the number of cells which have an expected count of less than 5. In Fig 1, from a total of 167 subjects, 91(54.5\%) females were diagnosed left knee $\mathrm{OA}, 63(37.7 \%)$ diagnosed as right knee $\mathrm{OA}$ and $13(7.8 \%)$ were affected bilaterally.

\begin{tabular}{|l|l|l|l|l|}
\hline \multicolumn{5}{|c|}{ Table l: Descriptive statistics of the respondents' age. } \\
\hline $\begin{array}{l}\text { Age of the } \\
\text { respondent }\end{array}$ & Mean & SD & Minimum & Maximum \\
\hline 167 & 58.33 & 8.836 & 45 & 82 \\
\hline
\end{tabular}

Table II: Shows Difficulty during Activities of Daily Life (WOMAC Osteoarthritis Index Questionnaire)

\begin{tabular}{l|c|c|c|}
\hline & Chi Square & $\begin{array}{l}\text { df (Degree } \\
\text { of freedom) }\end{array}$ & P value \\
\hline $\begin{array}{l}\text { Knee OA * Difficulty while } \\
\text { ascending stairs }\end{array}$ & $15.252^{\mathrm{a}}$ & 6 & 0.018 \\
\hline
\end{tabular}

ascending stairs 0.018

The 5 cells $(41.7 \%)$ expected count $<5$. The minimum expected coun is 0.78 .

\begin{tabular}{l|c|c|c|}
\hline $\begin{array}{l}\text { Knee OA * Difficulty while } \\
\text { descending stairs }\end{array}$ & $11.539 a$ & 6 & 0.073 \\
\hline
\end{tabular}

The 5 cells $(41.7 \%)$ expected count $<5$. The minimum expected count is 0.70 .

\begin{tabular}{l|c|c|c|}
$\begin{array}{l}\text { Knee OA * Difficulty in rising } \\
\text { from sitting }\end{array}$ & $25.928^{\mathrm{a}}$ & 8 & 0.002 \\
\hline
\end{tabular}

The 8 cells $(53.3 \%)$ expected count $<5$. The minimum expected count is 0.08 .

Knee OA * Difficulty in

13.089a

6

0.042

bending to floor

0.042

The 5 cells $(41.7 \%)$ expected count $<5$. The minimum expected count is 0.39 .

\begin{tabular}{l|l|l|l|}
$\begin{array}{l}\text { Knee OA * Difficulty in } \\
\text { standing }\end{array}$ & $28.136^{\mathrm{a}}$ & 8 & 0.005 \\
\hline
\end{tabular}

The 9 cells $(60.0 \%)$ expected count $<5$. The minimum expected count is 0.23 .

\begin{tabular}{l|c|c|c|}
$\begin{array}{l}\text { Knee OA * Difficulty in } \\
\text { walking on flat surface }\end{array}$ & $11.282^{\mathrm{a}}$ & 8 & 0.186 \\
\hline
\end{tabular}

The 8 cells $(53.3 \%)$ expected count $<5$. The minimum expected count is 0.39 .

Knee OA * Difficulty in

22.918

8

0.003

getting inlout of car

$<5$. The minimum expected count The 7 cells
is 0.23 .

Knee $O A$ * Difficulty in going

14.779a

8

0.064

shopping

$<$. The minimum expected count

The 8 ce

is 0.08 .

\begin{tabular}{l|c|c|c|}
$\begin{array}{l}\text { Knee OA * Difficulty in } \\
\text { putting on socks }\end{array}$ & $15.8364^{a}$ & 8 & 0.045 \\
\hline
\end{tabular}

\begin{tabular}{l|l|l}
$15.8364^{\mathrm{a}}$ & 8 & 0.045
\end{tabular}

The 8 cells $(53.3 \%)$ expected count $<5$. The minimum expected count is 0.23 .

\begin{tabular}{|l|l|l|l|}
\hline Knee OA * Difficulty in rising & $14.562^{\mathrm{a}}$ & 8 & 0.068 \\
\hline
\end{tabular}

from bed 7 cells $(46.7 \%)$ expected count $<5$. The minimum expected count is 0.08 .

\begin{tabular}{|l|l|l|l|}
\hline Knee OA * Difficulty in & $26.672^{\mathrm{a}}$ & 8 & 0.001 \\
\hline
\end{tabular}

The 8 cells $(53.3 \%)$ expected count $<5$. The minimum expected count is 0.08 .

\begin{tabular}{|l|l|l|l|}
\hline Knee OA * Difficulty in lying & 7.129 a & 6 & 0.309 \\
\hline
\end{tabular}

in bed 6 cells $(50.0 \%)$ expected count $<5$. The minimum expected count is 0.62 .
Knee OA * Difficulty in/out

of bath

17.569 a

8

0.024

The 8 cells $(53.3 \%)$ expected count $<5$. The minimum expected count is 0.16 .

Knee OA * Difficulty in

sitting

$9.135^{\mathrm{a}}$

8

0.316

The 8 cells $(53.3 \%)$ expected count $<5$. The minimum expected count is 0.16 .

\begin{tabular}{|l|l|l|l|}
\hline Knee OA * Difficulty in & $17.907^{a}$ & 8 & 0.022 \\
\hline
\end{tabular}

getting on/off toile

is 0.54 .

Knee OA * Difficulty in

heavy domestic duties

$7.702^{\mathrm{a}}$

6

0.103

The 5 cells $(41.7 \%)$ expected count $<5$. The minimum expected count is 0.08 .

Knee $O A *$ Difficulty in light

domestic duties

12.692a

8

0.125

The 8 cells $(53.3 \%)$ expected count $<5$. The minimum expected count is 0.39 .

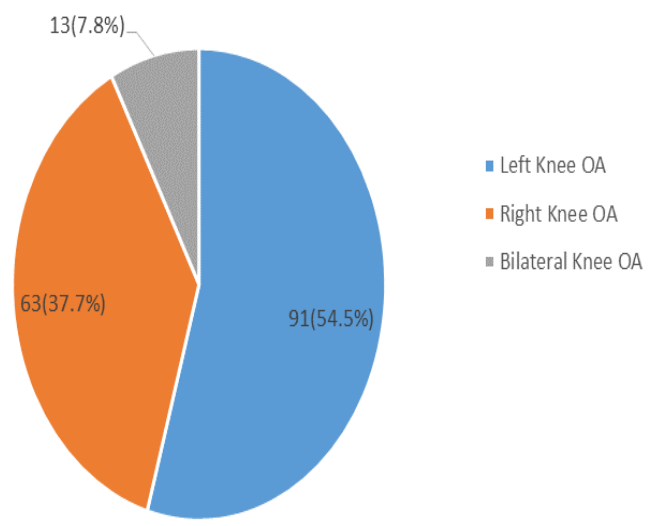

Figure 1. Descriptive statistics of knee OA ( $n=167)$

$$
\text { Discussion }
$$

Current study was executed to conclude an association between knee $\mathrm{OA}$ and difficulty in activities of routine life in elderly females in a study sample which consisted of total 167 individuals from a wide-ranging age group from $45-82$ years in which the greatest $54.5 \%$ of females were diagnosed of left knee OA, $37.7 \%$ of right knee $\mathrm{OA}$ and $7.8 \%$ of bilateral knee $\mathrm{OA}$. The existing study established that elderly females with osteoarthritis of the knee joint had trouble during performing ADL's.

Comparable to our study, an investigation which was held in Japan decided that females diagnosed with $\mathrm{OA}$ of the knee had increased pain in the knee joint while descending the stairs as related to ascending the staircase.

However, according to our study, females reported greater range of difficulty while ascending stairs rather than descending stairs which is mainly due to the gravity assistance which descending and lesser degree of axial pull on the knee joint. Moreover, other activities were 
also noted to have a broader view of the difficulties faced by the females. ${ }^{6}$

A significant association was proved between knee $\mathrm{OA}$ and difficulty during ascending stairs (0.018), difficulty during rising from sitting (0.002), difficulty during bending to floor (0.042), difficulty during getting in/out of car (0.03), difficulty in putting on socks (0.045), difficulty in taking off socks (0.001), difficulty getting in/out of bath $(0.024)$ and difficulty during on/off toile $(0.022)$ in the osteoarthritis patients.

However, insignificant associations were present in some activities with knee OA such as difficulty during descending stairs $(0.073)$, difficulty during standing $(0.05)$, difficulty during walking on flat surface(.186), difficulty during rising from bed(0.64), difficulty in lying in bed (0.309), difficulty in going shopping(.316), difficulty during light domestic duties(.125),difficulty during heavy domestic duties (1.25)

This elaborates further that not all activities are positively associated with knee osteoarthritis in elderly females although some of it that are associated may have a higher impact on the progression of the disease.

There are few limitations of this study which need to be addressed such as, the association was checked with generalized knee pain, the exact location of pain whether it is isolated medial or patellofemoral or tibiofemoral was not investigated. However, present study will assist the future researchers in this case.

\section{Conclusion}

Knee osteoarthritis is a condition that affects people worldwide and is one of the disease related disability. Knee osteoarthritis results in long term joint pain and limitation of physical functioning even the tasks of daily living were also affected which will cause impaired quality of life. This study concluded that a positive association exists between knee $O A$ and difficulty during activities of daily life in elderly females. This means that elderly females diagnosed with knee OA are more prone to face difficulty in different types of daily routine activities.

References
1. Hinman RS, Hunt MA, Creaby MW, Wrigley TV, McManus FJ, Bennell KL. Hip muscle weakness in individuals with medial knee osteoarthritis. Arthritis care \& research. 2010;62(8):1190-3.

2. Foroughi N, Smith RM, Lange AK, Baker MK, Singh MAF, Vanwanseele B. Lower limb muscle strengthening does not change frontal plane moments in women with knee osteoarthritis: a randomized controlled trial. Clinical biomechanics. 2011;26(2):167-74.

3. Hensor EM, Dube B, Kingsbury SR, Tennant A, Conaghan PG. Toward a clinical definition of early osteoarthritis: Onset of patient-reported knee pain begins on stairs. Data from the osteoarthritis initiative. Arthritis care \& research. 2015;67(1):40-7.

4. Fukutani N, lijima H, Aoyama T, Yamamoto Y, Hiraoka M, Miyanobu K, et al. Knee pain during activities of daily living and its relationship with physical activity in patients with early and severe knee osteoarthritis. Clinical rheumatology. 2016;35(9):2307-16.

5. Bennell $K$, Hunt $M$, Wrigley $T$, Hunter D, McManus $F$, Hodges $\mathrm{P}$, et al. Hip strengthening reduces symptoms but not knee load in people with medial knee osteoarthritis and varus malalignment: a randomised controlled trial. Osteoarthritis and Cartilage. 2010;18(5):621-8.

6. Akai M, Doi T, Fujino K, Iwaya T, Kurosawa H, Nasu T. An outcome measure for Japanese people with knee osteoarthritis. The Journal of rheumatology. 2005;32(8):1524-32.

7. lijima $H$, Aoyama $T$, Fukutani $N$, Isho $T$, Yamamoto $Y$, Hiraoka M, et al. Psychological health is associated with knee pain and physical function in patients with knee osteoarthritis: an exploratory cross-sectional study. BMC psychology. 2018;6(1):19.

8. Palazzo C, Nguyen C, Lefevre-Colau M-M, Rannou F, Poiraudeau S. Risk factors and burden of osteoarthritis. Annals of physical and rehabilitation medicine. 2016;59(3):134-8.

9. Nguyen C, Lefevre-Colau M-M, Poiraudeau S, Rannou F. Rehabilitation (exercise and strength training) and osteoarthritis: a critical narrative review. Annals of physical and rehabilitation medicine. 2016;59(3):190-5.

10. Rannou F, Poiraudeau S. Non-pharmacological approaches for the treatment of osteoarthritis. Best practice \& research Clinical rheumatology. 2010;24(1):93106.

11. Salsich GB, Brechter JH, Powers CM. Lower extremity kinetics during stair ambulation in patients with and without patellofemoral pain. Clinical Biomechanics. 2001;16(10):906-12.

12. Juhl $C B$, Christensen RDK, Roos EM, Zhang W, Lund $H$. Impact of exercise type and dose on pain and disability in knee osteoarthritis: A systematic review and metaregression analysis. Osteoarthritis and Cartilage. 2011;19(Supplement 1):42. 